\title{
Cone-Beam Computed Tomography Evaluation of the Positions of Unerupted Maxillary Canines with Incisor Root Resorption
}

\author{
Sachio Tamaoki ${ }^{*}$, Hiroyuki Ishikawa ${ }^{2}$, Kyoko Oka ${ }^{3}$, Masao Ozaki ${ }^{3}$, Akiko Abe ${ }^{1}$, \\ Shunsuke Takata ${ }^{1}$, Shozaburo Hata ${ }^{1}$
}

\author{
${ }^{1}$ Section of Orthodontics, Department of Oral Growth \& Development, Division of Clinical Dentistry, Fukuoka Dental College, \\ Fukuoka, Japan \\ ${ }^{2}$ Fukuoka Dental College, Fukuoka, Japan \\ ${ }^{3}$ Section of Pediatric Dentistry, Department of Oral Growth \& Development, Division of Clinical Dentistry, Fukuoka Dental \\ College, Fukuoka, Japan \\ Email: `tama@college.fdcnet.ac.jp, ishiro@college.fdcnet.ac.jp, okak@college.fdcnet.ac.jp, mozaki@college.fdcnet.ac.jp, \\ pcame@college.fdcnet.ac.jp, mabuya@college.fdcnet.ac.jp, shozabu@college.fdcnet.ac.jp
}

How to cite this paper: Tamaoki, S., Ishikawa, H., Oka, K., Ozaki, M., Abe, A., Takata, S. and Hata, S. (2017) Cone-Beam Computed Tomography Evaluation of the Positions of Unerupted Maxillary Canines with Incisor Root Resorption. Open Journal of Stomatology, 7, 169-179. https://doi.org/10.4236/ojst.2017.73012

Received: February 12, 2017

Accepted: March 20, 2017

Published: March 23, 2017

Copyright $\odot 2017$ by authors and Scientific Research Publishing Inc. This work is licensed under the Creative Commons Attribution International License (CC BY 4.0).

http://creativecommons.org/licenses/by/4.0/ c) (i) Open Access

\begin{abstract}
Purpose: To establish a new coordinate system using the incisive canal and incisive foramen in cases confirmed to have root resorption in the maxillary incisor region by cone beam computed tomography (CBCT) to investigate the positions of the central and lateral incisor roots and erupting maxillary canine tooth crowns in the horizontal plane. Methods: Nine patients (two males; mean age: 10.5 years old) with suspected incisor root resorption due to erupting maxillary canines on panoramic X-ray images and in whom incisor root resorption was confirmed on $\mathrm{CBCT}$ images were evaluated. A control group of 12 patients with a supernumerary tooth on one side (three males; mean age: 8.6 years old) was also examined. $\mathrm{X}, \mathrm{Y}$, and $\mathrm{Z}$-axes were defined, and the positions of the centers of the central incisor root (U1) and lateral incisor root (U2) and the canine cusp (U3) were examined, along with alveolar process width and length. Results: In the control group, U1, U2, and U3 were located within a certain range without overlap, while, in the incisor root resorption group, U3 overlapped with $\mathrm{U} 1$ and $\mathrm{U} 2$ and tended to deviate centrally. U2 tended to be located further posteriorly than U3. The anteroposterior diameter of the alveolar process was $1.2 \mathrm{~mm}$ shorter in the incisor root resorption group $(p<0.05)$. Conclusions: The risk of incisor root resorption accompanying canine eruption can be evaluated early by investigating the canine position on a horizontal plane established on the upper anterior tooth dentition CT images with a coordinate system using the incisive canal and incisive foramen.
\end{abstract}


Keywords

CBCT, Incisor Root Resorption, Maxillary Canine, Incisive Canal, Alveolar Process

\section{Introduction}

Intraoral and panoramic radiography are performed to examine the state of eruption of non-erupted permanent teeth in children during the mixed dentition period [1] [2]. These X-ray images may show contact or overlap between erupting maxillary canine tooth crowns and maxillary lateral or central incisor roots [3]. In such cases, incisor root resorption may be suspected and confirmed on two-dimensional imaging [4]. If root resorption is present, particularly in the labiolingual direction, the presence or absence of incisor root resorption can be difficult to determine [5].

Since 1990, computed tomography (CT) has been used to determine the presence of incisor root resorption. Ericson and Kurol [6] used CT images to evaluate the state of root resorption after establishing grades for incisor root resorption. Walker et al. [7] were the first to report short distances between lateral incisors and canines based on an investigation of occlusal plane axial CT images from 19 subjects in whom incisor root resorption was suspected. Cone-beam CT ( СBCT), which takes images at even higher resolutions than CT, was later used to confirm incisor root resorption [8]. However, as the imaging range for CBCT is narrow and anatomical structures that can be used as references for measurements are lacing, few studies have conducted quantitative analyses of canine and incisor positions in the horizontal plane.

The present study therefore established a new coordinate system using the incisive canal and incisive foramen in cases with confirmed root resorption in the maxillary incisor region on CBCT images to investigate the positions of the central and lateral incisor roots and erupting maxillary canine tooth crowns in the horizontal plane. These results were then compared with those from a control group that did not exhibit any incisor root resorption.

\section{Materials and Methods}

Subjects were selected among patients 8 to 14 years of age who visited the Orthodontic Clinic at Fukuoka Dental College Medical \& Dental Hospital between 2010 and 2014. The range of age was determined so that we would meet patients with fully erupted maxillary incisors and uncompleted root formation of maxillary canines. Patients with congenital malformation, a history of trauma to the anterior tooth region, abnormal numbers of permanent teeth in the upper anterior tooth dentition, or lateral incisor microdontia were excluded. Nine patients (two males, seven females; mean age: 10.5 years old) in whom incisor root resorption due to erupting maxillary canines was suspected on panoramic X-ray taken at the initial examination and in whom incisor root resorption was actual- 
ly confirmed on CBCT were selected as subjects for analysis. CBCT was used to determine the presence or absence of maxillary incisor root resorption based on axial tomography of the incisors. Used the root resorption grades defined by Ericson and Kurol [6], root resorption was determined to be present in patients who were grade 2 (resorption in less than half of the incisor dentin), grade 3 (resorption of at least half of the incisor dentin, but not reaching the dental pulp), or grade 4 (resorption reaching the dental pulp). Among these nine patients, bilateral root resorption was noted in three and unilateral root resorption was noted in six. CBCT volume data from the 12 sites, including the canines causing incisor root resorption in these patients along with the central and lateral incisors on the affected side, were used as data in the incisor root resorption group.

For the control group, 12 patients with a supernumerary tooth on one side (three males, nine females; mean age: 8.6 years) were examined. CBCT volume data from the 12 sites, including three anterior teeth on the unaffected side with no supernumerary teeth, were used as data in the control group. The Ethics Committee of Fukuoka Dental College approved all protocols for this retrospective study.

\subsection{Measurement of Anteroposterior and Left-Right Positions of Canine Crowns and Incisor Roots on CBCT Images}

CBCT was conducted using a 3DX multi-image micro-CT system (FPD8; MORITA, Kyoto, Japan). Fixation of the head position was achieved using head strap and chin cup, and the Frankfort horizontal (FH) and median sagittal planes were normalized using laser light applied to the facial skin surface as a guide. Imaging conditions were as follows: tube voltage, $80 \mathrm{kV}$; tube current, 8 $\mathrm{mA}$; $180^{\circ}$ imaging; diameter, $60 \mathrm{~mm}$; height, $60 \mathrm{~mm}$; and voxel size, $125 \mu \mathrm{m}$. СBCT data were saved in the DICOM format and were measured by using an $\mathrm{X}$-ray viewing monitor (RadiForce GS220; EIZO, Shiroyama, Japan).

Tomographic images were created and measured by using a three-dimensional imaging viewer (PACS version 3.0; INFINITT Healthcare, Seoul, Korea). First, sagittal images were created from CBCT DICOM data as reported by Thakur et al. [9], and an image was selected in which the incisive canal appeared to be centered. The image was rotated such that the posterior wall portion of the incisive canal was perpendicular to the FH plane on $\mathrm{CT}$ imaging. The incisive canal was thus upright and perpendicular to the basal plane on the viewer window (Figure 1).

The most posterior point in the incisive foramen contour on the image was the incisive fossa (IFo) and was used as the origin, with the posterior wall of the upright incisive canal set as the Z-axis. Next, the most anterior point in the median palatine suture was positioned on the tomographic image along the $Z$-axis, and the line joining this point and the IFo was set as the $\mathrm{Y}$-axis. The $\mathrm{X}$-axis was set perpendicular to both the $\mathrm{Z}$ - and $\mathrm{Y}$-axes. The resulting $\mathrm{XY}$ plane was set as a new tomographic plane, and XY coordinates were acquired with the center of 

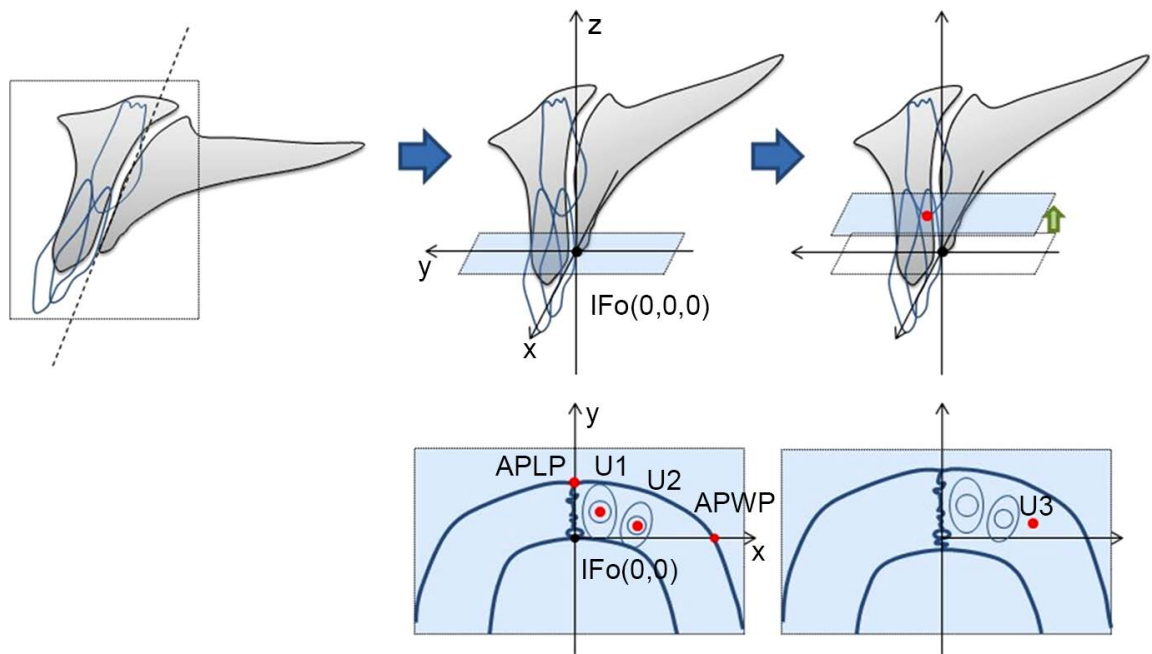

Figure 1. Measurement method using three-dimensional CBCT tomographic images. IFo $(0,0,0)$ : Most posterior point of the posterior margin of the incisive foramen (IFo: incisive fossa).

the central incisor root as $\mathrm{U} 1$ and the center of the lateral incisor root as U2. To project canine cusp XY coordinates onto this tomographic plane, the XY plane was moved along the $\mathrm{Z}$-axis and an image depicting the erupting canine cusp was searched for. The XY coordinates on the image were then acquired with the canine cusp set as U3. For U3, Z-axis coordinates were also acquired, and were considered to indicate the vertical canine position in relation to the tomographic plane including the IFo (Figure 1). The same coordinate system was set up for CBCT DICOM data in the control group; the same coordinate values were acquired for the centers of the central and lateral incisor roots and for the canine cusp on the unaffected side with no supernumerary teeth.

Next, the width of the anterior alveolar process and its anteroposterior diameter on the tomographic plane including the IFo were measured. The point of intersection between the lateral external surface of the upper alveolar bone and the $\mathrm{X}$-axis was set as the alveolar process width point (APWP), with the value of this $\mathrm{X}$-axis coordinate considered as the alveolar process width (APW). The point of intersection between the external surface of the alveolar bone anterior and the $\mathrm{Y}$-axis was set as the alveolar process length point (APLP), and the value of this $\mathrm{Y}$-axis coordinate was considered as the alveolar process length (APL), referring to the anteroposterior diameter of the alveolar process (Table 1). The APW and APL in the control group were measured in a similar manner.

To combine data from the left and right sides, $\mathrm{X}$-axis values were inverted only for coordinate data on the right side, to allow comparison with measurement results from the left side.

\subsection{Statistical Analysis}

In the control and incisor root resorption groups, one-way analysis of variance (ANOVA) for the $\mathrm{X}$ - and $\mathrm{Y}$-axis coordinates of the central and lateral incisors and canines was performed. Multiple comparisons with Bonferroni correction 
Table 1. Abbreviation list of measurement points.

\begin{tabular}{|c|c|}
\hline Abbreviations & Definitions \\
\hline IFo (incisive fossa) & $\begin{array}{l}\text { Most posterior point of the posterior margin } \\
\text { of the incisive foramen }\end{array}$ \\
\hline $\mathrm{U} 1$ & Center point of central incisor root \\
\hline $\mathrm{U} 2$ & Center point of lateral incisor root \\
\hline U3 & Projected canine cusp point \\
\hline APWP (alveolar process width point) & $\begin{array}{l}\text { Point of intersection between the lateral external } \\
\text { surface of the upper alveolar bone and the } \mathrm{X} \text {-axis }\end{array}$ \\
\hline APLP (alveolar process length point) & $\begin{array}{l}\text { Point of intersection between the anterior external } \\
\text { surface of the upper alveolar bone and the Y-axis }\end{array}$ \\
\hline APW & Alveolar process width \\
\hline APL & Alveolar process length \\
\hline
\end{tabular}

were then performed to evaluate differences in the anteroposterior and left-right positions of teeth in the horizontal plane. Next, an F test was performed for each coordinate value and the APW and APL for the three anterior teeth, before applying the Mann-Whitney U test.

To evaluate measurement error, each coordinate value of the three anterior teeth and the APW and APL were measured for 10 randomly selected sites twice, with an interval of at least four weeks. Houston's method [10] was used to calculate measurement error. The calculated measurement error was within the range of $0.1 \mathrm{~mm}$ to $0.2 \mathrm{~mm}$, with an acceptable confidence coefficient of at least 0.89 (Table 2).

\section{Results}

Control and incisor root resorption group results for U1, U2, U3, APW, and APL on the XY plane with IFo as the origin are provided in Figure 2. In the control group, points U1, U2, and U3 were located within a certain range and did not overlap. In contrast, in the incisor root resorption group, the area of U3 overlapped with that of $\mathrm{U} 1$ and $\mathrm{U} 2$ and tended to deviate toward the center. U2 tended to be located further posteriorly than U3.

Figure 3 shows the results for multiple comparisons after Bonferroni correction for the $\mathrm{X}$ - and $\mathrm{Y}$-axis coordinates of $\mathrm{U} 1, \mathrm{U} 2$ and $\mathrm{U} 3$ after ANOVA. In the control group, significant differences were noted in $\mathrm{X}$-coordinate values between $\mathrm{U} 1, \mathrm{U} 2$, and $\mathrm{U} 3$ and in $\mathrm{Y}$-coordinate values between $\mathrm{U} 1$ and $\mathrm{U} 2$ and between $\mathrm{U} 1$ and $\mathrm{U} 3(p<0.01)$. In the incisor root resorption group, significant differences were noted in $\mathrm{X}$-coordinate values between $\mathrm{U} 1$ and $\mathrm{U} 2$ and between $\mathrm{U} 1$ and $\mathrm{U} 3$ and in $\mathrm{Y}$ coordinate values between $\mathrm{U} 1, \mathrm{U} 2$, and $\mathrm{U} 3(p<0.05$ and $p<0.01)$.

Table 3 shows the results of measurements for the positions of U1, U2, and U3 as well as of APL and APW between groups. No significant differences were noted in either X- or Y-axis coordinates for U1. U2 showed no significant dif- 
ference in the $\mathrm{X}$-axis coordinate, but was significantly smaller along the $\mathrm{Y}$-axis in the incisor root resorption group $(p<0.01)$, indicating that the lateral incisor was located further posteriorly compared to the control group. For U3, significant differences were noted for the $\mathrm{X}$ - and $\mathrm{Y}$-axis coordinates $(p<0.01)$, with the canine found to be positioned more medially and anteriorly in the incisor root resorption group than in the control group. No significant differences were noted between groups for $\mathrm{U} 3$ on the $\mathrm{Z}$-axis, indicating no differences in vertical direction for the canine. In terms of the alveolar process, no significant difference was noted for the APW, but a significant difference was seen for the APL ( $p$ $<0.05$ ); with the anteroposterior diameter of the alveolar process shorter in the incisor root resorption group than in the control group.

Table 2. Measurement errors for three-dimensional CBCT tomographic images.

\begin{tabular}{ccc}
\hline & Combined error $(\mathrm{mm})$ & Coefficient of reliability \\
\hline U1 (x) & 0.19 & 0.885 \\
U1 (y) & 0.16 & 0.985 \\
U2 (x) & 0.17 & 0.994 \\
U2 (y) & 0.15 & 0.983 \\
U3 (x) & 0.13 & 0.998 \\
U3 (y) & 0.18 & 0.973 \\
U3 (z) & 0.17 & 0.998 \\
APW & 0.17 & 0.989 \\
APL & 0.20 & 0.971 \\
\hline
\end{tabular}

Table 3. Results of measurements on tomographic images with the incisive foramen as the reference point for the incisor root resorption and control groups.

\begin{tabular}{ccccc}
\hline & $\begin{array}{c}\text { Control group } \\
(\mathrm{n}=12)\end{array}$ & $\begin{array}{c}\text { Incisor root resorption } \\
\text { group }(\mathrm{n}=12)\end{array}$ & F test & $\begin{array}{c}\text { Mann-Whitney } \\
\text { U test }\end{array}$ \\
\hline $\mathrm{U} 1(\mathrm{x})$ & $3.75 \pm 1.10$ & $3.41 \pm 0.58$ & $0.047^{*}$ & 0.364 \\
$\mathrm{U} 1(\mathrm{y})$ & $7.14 \pm 1.54$ & $6.67 \pm 1.40$ & 0.752 & 0.439 \\
$\mathrm{U} 2(\mathrm{x})$ & $8.46 \pm 1.36$ & $7.27 \pm 2.47$ & 0.059 & 0.160 \\
$\mathrm{U} 2(\mathrm{y})$ & $3.87 \pm 0.86$ & $2.16 \pm 1.24$ & 0.237 & $0.001^{* *}$ \\
$\mathrm{U} 3(\mathrm{x})$ & $13.81 \pm 1.66$ & $8.80 \pm 2.88$ & 0.081 & $0.0001^{* *}$ \\
$\mathrm{U} 3(\mathrm{y})$ & $3.47 \pm 2.69$ & $5.30 \pm 1.16$ & $0.010^{* *}$ & $0.0046^{* *}$ \\
$\mathrm{U} 3(\mathrm{z})$ & $-0.81 \pm 1.88$ & $-2.03 \pm 3.78$ & $0.029^{*}$ & 0.335 \\
$\mathrm{APW}$ & $21.61 \pm 1.66$ & $21.30 \pm 1.67$ & 0.976 & 0.648 \\
APL & $11.47 \pm 1.41$ & $10.28 \pm 1.22$ & 0.642 & $0.038^{*}$ \\
\hline
\end{tabular}

${ }^{*} p<0.05,{ }^{* *} p<0.01$. 

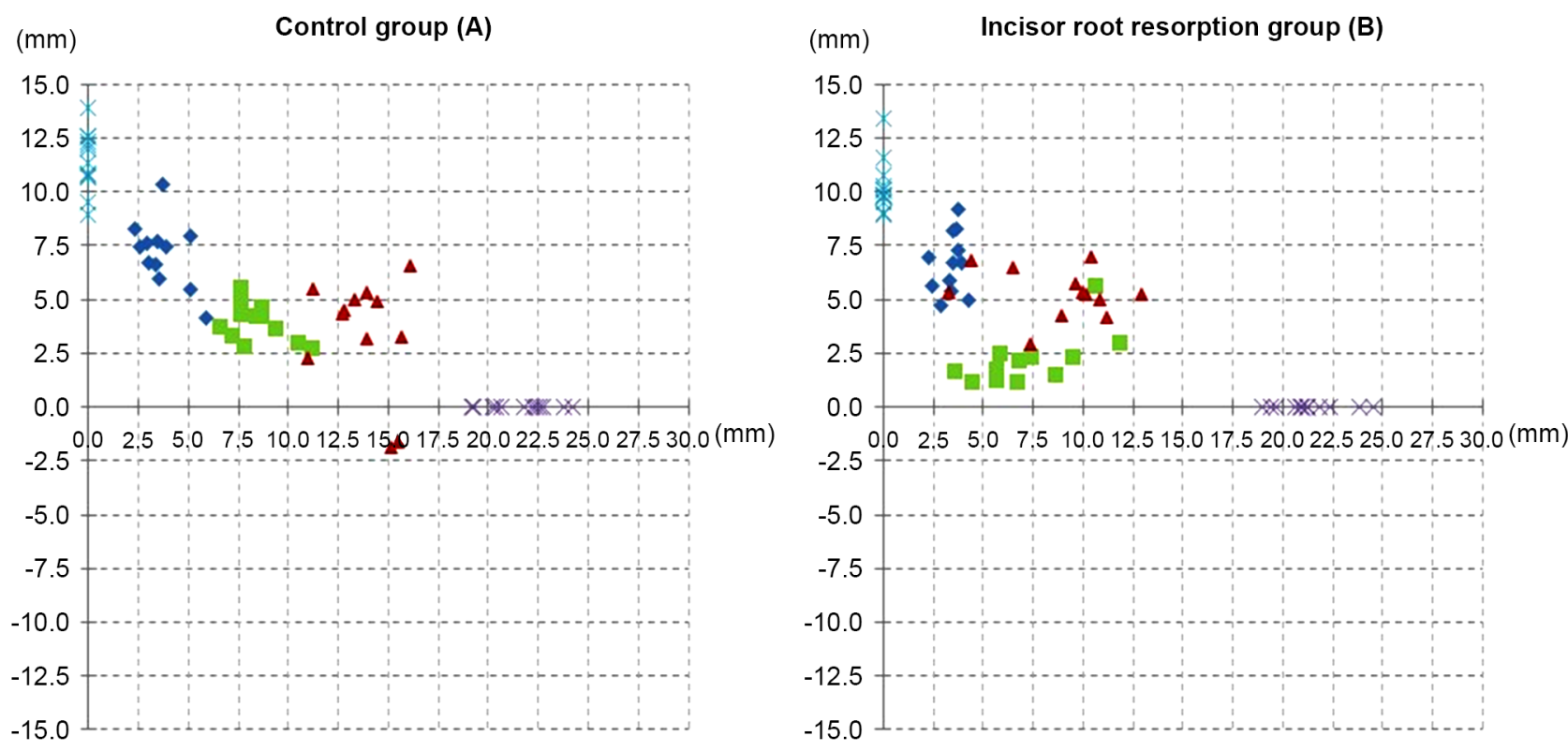

Figure 2. Incisor, canine, and alveolar base position on the tomographic plane with the incisive foramen as the origin in the control group (A) and the incisor root resorption group (B). $\diamond: \mathrm{U} 1, \square: \mathrm{U} 2, \boldsymbol{\Delta}: \mathrm{U} 3, \times:$ APWP (alveolar process width point), $*$ : APLP (alveolar process length point). Origin $(0,0)$ : Most posterior point of the posterior margin of the incisive foramen (IFo: incisive fossa).
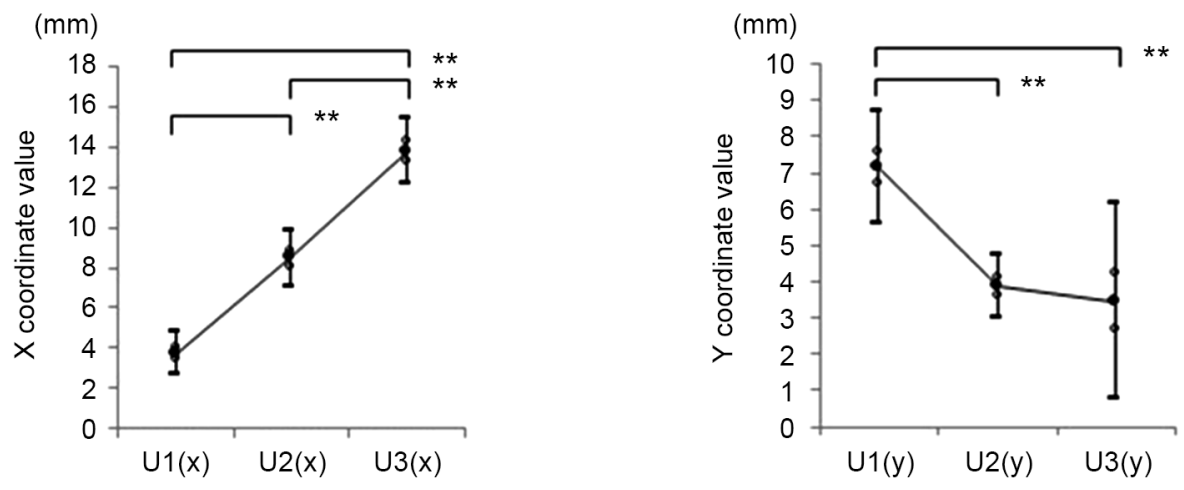

Control group (A)
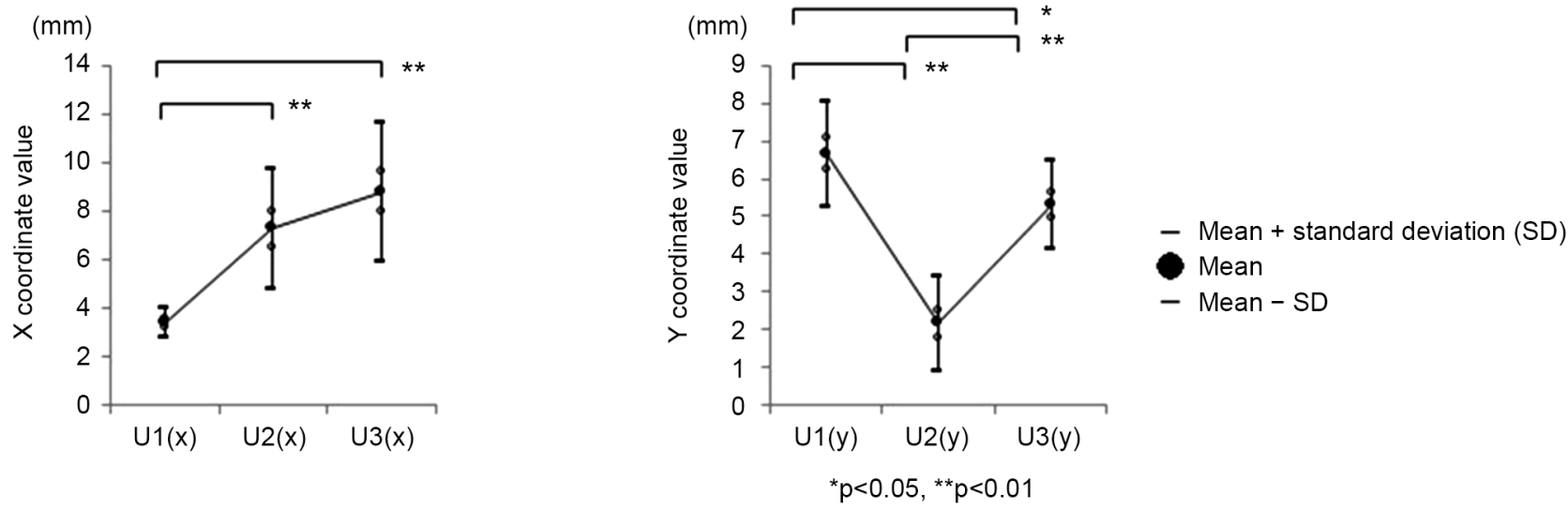

Incisor root resorption group (B)

Figure 3. Multiple comparisons with Bonferroni correction of the positions of the central incisor, lateral incisor and canine in the control group (A) and the incisor root resorption group (B). 


\section{Discussion}

This study used a measurement system that takes CBCT images with the posterior wall of the incisive canal upright in the perpendicular direction to allow measurement of canine and incisor positions on the horizontal plane as well as of the width and anteroposterior diameter of the anterior alveolar process. With this method, when incisor root resorption due to erupting canines is present, the position of the canine cusp in relation to the lateral incisor is more central in the $\mathrm{X}$-axis direction and more anterior in the $\mathrm{Y}$-axis direction than in the control group with no root resorption. Furthermore, when incisor root resorption is present, the lateral incisors are positioned on the lingual side in the alveolar bone and the anterior alveolar bone shows a small anteroposterior diameter. The sample size was relatively small, but was considered acceptable from sample size estimation by the retrospective power analysis for each variable that showed a statistically significant difference between the two groups.

For the canine position in cases with incisor root resorption, Ericson and $\mathrm{Ku}-$ rol [11] defined five sectors on intraoral occlusal films of patients who exhibited lateral incisor root resorption due to canine eruption and evaluated canine positioning in the buccolingual direction per sector. According to that study, in such patients, canine cusps were more likely to be positioned in medial sectors than in the normal group, consistent with the present results. Sambataro et al. [12] investigated buccolingual positions of the canine cusps and incisor roots using posteroanterior X-ray images, revealing that when the canines are impacted, the canine cusps are buccolingually inclined on the lingual side, which appears consistent with our results. Walker et al. [7] established a horizontal plane on upper jaw CT images including the maxillary canine cusps and measured tooth positions on this plane. They found that in cases showing incisor root resorption or contact between the incisor and erupting canine, mean buccolingual distance between the canine cusp and center of the lateral incisor was $1.4 \mathrm{~mm}$. This distance is similar to the mean distance of $1.53 \mathrm{~mm}$ between $\mathrm{U} 2$ and $\mathrm{U} 3$ along the $\mathrm{X}$-axis in the incisor root resorption group of the present study. The risk of incisor root resorption thus appears to increase when canine cusp position is closer to the midline, resulting in the center of the root of the lateral incisor being close to the canine cusp in the buccolingual direction.

To date, few reports have reported on the canine anteroposterior position in patients exhibiting incisor root resorption. Ericson and Kurol [11] used panoramic X-rays of patients who exhibited lateral incisor root resorption due to canine eruption and defined five sectors on images from the mesial position to evaluate the mesiodistal position of the canine cusp per sector. They reported that the canine cusp was in a more mesial sector in the group exhibiting root resorption than in the normal group, consistent with the trends observed in the present study for the canine anteroposterior position in the incisor root resorption group. For three-dimensional images, Oberoi and Knueppel [13] set up a coordinate system using the left and right optical nerve canals in the cranial base on relatively wide-ranging $\mathrm{CBCT}$ images and measured the impacted canine po- 
sition. Their results showed that in $93 \%$ of patients, the cusps of impacted canines were positioned an average of $10.1 \mathrm{~mm}$ more anteriorly in the horizontal plane than the canine cusps on the unaffected side, consistent with the present findings for the incisor root resorption group.

In recent years, $\mathrm{CBCT}$ has come to be used to confirm the three-dimensional positions of erupting canines and incisor roots, as well as the presence or absence of root resorption. Although this imaging modality is useful for confirming root resorption due to the high resolution, guidelines [14] recommend that the CBCT volume size should be reduced, because wider imaging ranges are associated with increased radiation exposure and lower resolution. The imaging range for confirming incisor root resorption is limited to the immediate surroundings of the anterior teeth. However, a coordination system using the incisive canal and incisive foramen, as conducted in this study, appears useful for quantitative evaluation of the position of impacted canines. Thakur et al. [9] reported 4 types of the incisive canal: a slanted canal, a slanted-curved canal, a vertical canal, and a vertical-curved canal. Further study should be conducted to investigate the influence of the incisive canal types on setting the coordinate system.

This study started from the hypothesis that a small upper anterior alveolar process induces contact between the canine and incisor, making the individual prone to resorption of the root of the incisor. We then compared the width and anteroposterior diameter of the anterior alveolar process between the incisor root resorption and control groups. Although the results showed no significant differences in width between groups, anteroposterior diameter was significantly smaller in the incisor root resorption group. In terms of width, Langberg and Peck [15] reported no differences between an impacted canine group and a control group. Al-Nimri and Gharaibeh [16] reported a larger upper alveolar width in the impacted canine group. The results of the present study suggest that a small width of the alveolar bone is not a factor associated with incisor root resorption caused by canines, and the two aforementioned studies also appear to support this. However, we were unable to identify any studies that investigated the relationship between canine impaction and anteroposterior diameter of the alveolar bone. In the present study, lateral incisor roots were found to be positioned on the lingual side in the incisor root resorption group. This suggests that when the anteroposterior diameter of the alveolar bone is small, the eruption force of the medially located canine is easily applied to the lateral incisor root, resulting in posterior movement of the lateral incisor. As some studies have reported that upper canine eruption pressure causes lateral incisor root resorption [1] [6] [8], it appears that when the anteroposterior diameter of the alveolar bone in the upper anterior tooth region is small, eruption pressure from the maxillary canine is liable to cause root resorption as well as posterior movement of the lateral incisor.

\section{Conclusion}

Our results suggest that the risk of incisor root resorption increases when on the 
CBCT horizontal plane, erupting canine cusps are positioned anteriorly and medially, the anteroposterior diameter of the alveolar process in the upper anterior tooth region is narrow, and the lateral incisor roots are positioned on the lingual side. The risk of incisor root resorption accompanying canine eruption would be able to be evaluated early by investigating canine position on a horizontal plane established on CT images of the upper anterior tooth region with a coordination system using the incisive canal and incisive foramen.

\section{References}

[1] Fernández, E., Bravo, L.A. and Canteras, M. (1998) Eruption of the Permanent Upper Canine: A Radiologic Study. American Journal of Orthodontics and Dentofacial Orthopaedics, 113, 414-420.

[2] Caminiti, M.F., Sandor, G.K., Giambattistini, C. and Tompson, B. (1998) Outcomes of the Surgical Exposure, Bonding and Eruption of 82 Impacted Maxillary Canines. Journal of the Canadian Dental Association, 64, 572-579.

[3] Lindauer, S.J., Rubenstein, L.K., Hang, W.M., Andersen, W.C. and Isaacson, R.J. (1992) Canine Impaction Identified Early with Panoramic Radiographs. Journal of the American Dental Association, 123, 91-92, 95-97. https://doi.org/10.14219/jada.archive.1992.0069

[4] Brusveen, E.M., Brudvik, P., Bøe, O.E. and Mavragani, M. (2012) Apical Root Resorption of Incisors after Orthodontic Treatment of Impacted Maxillary Canines: A Radiographic Study. American Journal of Orthodontics and Dentofacial Orthopedics, 141, 427-435. https://doi.org/10.1016/j.ajodo.2011.10.022

[5] Alqerban, A., Jacobs, R., Souza, P.C. and Willems, G. (2009) In-Vitro Comparison of 2 Cone-Beam Computed Tomography Systems and Panoramic Imaging for Detecting Simulated Canine Impaction-Induced External Root Resorption in Maxillary Lateral Incisors. American Journal of Orthodontics and Dentofacial Orthopedics, 136, 764.e1-764.e11. https://doi.org/10.1016/j.ajodo.2009.03.036

[6] Ericson, S. and Kurol, P.J. (2000) Resorption of Incisors after Ectopic Eruption of Maxillary Canines: A CT Study. The Angle Orthodontist, 70, 415-423.

[7] Walker, L., Enciso, R. and Mah, J. (2005) Three-Dimensional Localization of Maxillary Canines with Cone-Beam Computed Tomography. American Journal of Orthodontics and Dentofacial Orthopedics, 128, 418-423.

https://doi.org/10.1016/j.ajodo.2004.04.033

[8] Maini, A., Durning, P. and Drage, N. (2008) Resorption: Within or Without? The Benefit of Cone-Beam Computed Tomography when Diagnosing a Case of an Internal/External Resorption Defect. British Dental Journal, 204, 135-137. https://doi.org/10.1038/bdj.2008.50

[9] Thakur, A.R., Burde, K., Guttal, K. and Naikmasur, V.G. (2013) Anatomy and Morphology of the Nasopalatine Canal Using Cone-Beam Computed Tomography. Imaging Science in Dentistry, 43, 273-281. https://doi.org/10.5624/isd.2013.43.4.273

[10] Houston, W.J. (1983) The Analysis of Errors in Orthodontic Measurements. American Journal of Orthodontics, 83, 382-390.

[11] Ericson, S. and Kurol, J. (1988) Resorption of Maxillary Lateral Incisors Caused by Ectopic Eruption of the Canines: A Clinical and Radiographic Analysis of Predisposing Factors. American Journal of Orthodontics and Dentofacial Orthopedics, 94, 503-513. https://doi.org/10.1016/0889-5406(88)90008-X

[12] Sambataro, S., Baccetti, T., Franchi, L. and Antonini, F. (2005) Early Predictive Va- 
riables for Upper Canine Impaction as Derived from Posteroanterior Cephalograms. Angle Orthodontist, 75, 28-34.

[13] Oberoi, S. and Knueppel, S. (2012) Three-Dimensional Assessment of Impacted Canines and Root Resorption Using Cone Beam Computed Tomography. Oral Surgery, Oral Medicine, Oral Pathology, Oral Radiology, 113, 260-267. https://doi.org/10.1016/j.tripleo.2011.03.035

[14] American Academy of Oral and Maxillofacial Radiology (2013) Clinical Recommendations Regarding Use of Cone Beam Computed Tomography in Orthodontics. Oral Surgery, Oral Medicine, Oral Pathology, Oral Radiology, 116, 238-257. https://doi.org/10.1016/j.00oo.2013.06.002

[15] Langberg, B.J. and Peck, S. (2000) Adequacy of Maxillary Dental Arch Width in Patients with Palatally Displaced Canines. American Journal of Orthodontics and Dentofacial Orthopedics, 118, 220-223. https://doi.org/10.1067/mod.2000.104819

[16] Al-Nimri, K. and Gharaibeh, T. (2005) Space Conditions and Dental and Occlusal Features in Patients with Palatally Impacted Maxillary Canines: An Aetiological Study. European Journal of Orthodontics, 27, 461-465.

https://doi.org/10.1093/ejo/cji022

\section{Submit or recommend next manuscript to SCIRP and we will provide best service for you:}

Accepting pre-submission inquiries through Email, Facebook, LinkedIn, Twitter, etc. A wide selection of journals (inclusive of 9 subjects, more than 200 journals)

Providing 24-hour high-quality service

User-friendly online submission system

Fair and swift peer-review system

Efficient typesetting and proofreading procedure

Display of the result of downloads and visits, as well as the number of cited articles

Maximum dissemination of your research work

Submit your manuscript at: http://papersubmission.scirp.org/

Or contact ojst@scirp.org 